\title{
Sea wrack delivery and accumulation on islands: factors that mediate marine nutrient permeability
}

\author{
Sara B. Wickham ${ }^{1,2,8, *}$, Nancy Shackelford ${ }^{1,3}$, Chris T. Darimont ${ }^{2,4,5}$, \\ Wiebe Nijland ${ }^{1,2,6}$, Luba Y. Reshitnyk ${ }^{2}$, John D. Reynolds ${ }^{2,7}$, Brian M. Starzomski ${ }^{1,2}$ \\ ${ }^{1}$ School of Environmental Studies, University of Victoria, Victoria, British Columbia V8W 2Y2, Canada \\ ${ }^{2}$ Hakai Institute, Heriot Bay, British Columbia V0P 1H0, Canada \\ ${ }^{3}$ Institute of Arctic and Alpine Research, University of Colorado, 4001 Discovery Dr., Boulder, Colorado 80303, USA \\ ${ }^{4}$ Department of Geography, University of Victoria, Victoria, British Columbia V8W 3R4, Canada \\ ${ }^{5}$ Raincoast Conservation Foundation, Sidney, British Columbia V8L 3Y3, Canada \\ ${ }^{6}$ Department of Physical Geography, Utrecht University, 3508 TC Utrecht, The Netherlands \\ ${ }^{7}$ Earth to Ocean Research Group, Department of Biological Sciences, Simon Fraser University, Burnaby, British Columbia V5A 1S6, \\ Canada \\ ${ }^{8}$ Present address: School of Environment, Resources and Sustainability, University of Waterloo, Waterloo, Ontario N2L 3G1, Canada
}

\begin{abstract}
Sea wrack provides an important vector of marine-derived nutrients to many terrestrial environments. However, little is known about the processes that facilitate wrack transport, deposition, and accumulation on islands. Three broad factors can affect the stock of wrack along shorelines: the amount of potential donor habitat nearby, climatic events that dislodge seaweeds and transfer them ashore, and physical characteristics of shorelines that retain wrack at a site. To determine when, where, and how wrack accumulates on island shorelines, we surveyed 455 sites across 101 islands in coastal British Columbia, Canada. At each site, we recorded wrack biomass, species composition, and shoreline biogeographical characteristics. Additionally, over a period of 9 mo, we visited a smaller selection of sites $(n=3)$ every 2 mo to document temporal changes in wrack biomass and species composition. Dominant wrack species were Zostera marina, Fucus distichus, Macrocystis pyrifera, Nereocystis luetkeana, Pterygophora californica, and Phyllospadix spp. The amount of donor habitat positively affected the presence of accumulated biomass of sea wrack, whereas rocky substrates and shoreline slope negatively affected the presence of sea wrack biomass. Biomass was higher during winter months, and species diversity was higher during summer months. These results suggest that shorelines with specific characteristics have the capacity to accumulate wrack, thereby facilitating the transfer of marine-derived nutrients to the terrestrial environment.
\end{abstract}

KEY WORDS: Sea wrack - Marine-terrestrial subsidy $\cdot$ Spatial subsidy $\cdot$ Ecosystem connectivity Wrack deposition $\cdot$ Wrack accumulation $\cdot$ Macrophyte $\cdot$ British Columbia $\cdot$ Remote sensing

\section{INTRODUCTION}

Boundary dynamics provide a framework for investigating how ecosystem edges can affect the flow of materials from one environment to another. This framework describes permeability as an important factor in regulating the transport of nutrients and energy vectors across ecosystems (Wiens et al. 1985).

*Corresponding author: sara.wickham@uwaterloo.ca
Permeability, the degree to which a boundary may deflect the movement of vectors, depends on the boundary characteristics and the nature of the vector (Wiens et al. 1985). The permeability of marine subsidies at the coastal boundary may be particularly important on small islands that have large perimeter to area ratios, allowing marine resources to penetrate to the island's interior more easily than on larger islands

(C) The authors 2020. Open Access under Creative Commons by Attribution Licence. Use, distribution and reproduction are unrestricted. Authors and original publication must be credited. 
and potentially affecting species productivity and diversity (Polis \& Hurd 1996, Anderson \& Wait 2001).

Marine-terrestrial subsidies can take many forms. Bird guano (derived from marine resources) and discarded marine mollusk shells fertilize soils and increase plant productivity directly through nutrient additions (Anderson \& Polis 1999, McCauley et al. 2012, Trant et al. 2016). Beach-cast fish, carrion, marine mammal carcasses, and intertidal invertebrates provide nutrition to numerous vertebrate and invertebrate scavengers, increasing consumer populations (Polis \& Hurd 1996, Barrett et al. 2005). Despite fluctuating across both spatial and temporal scales, primary consumers (e.g. amphipods and isopods) will increase in abundance near these vectors of marine subsidy (Polis \& Hurd 1996, Colombini et al. 2000, Dugan et al. 2003, Ince et al. 2007, MacMillan \& Quijón 2012). Accordingly, secondary consumers such as birds, spiders, scorpions, lizards, and rodents will respond to the increased abundances of macroinvertebrates (Catenazzi \& Donnelly 2007, Spiller et al. 2010, Schlacher et al. 2017). Larger mammals, such as coyotes Canis latrans and black bears Ursus americanus, have also been observed to alter their spatial and temporal distribution in response to marine subsidies (Rose \& Polis 1998, Carlton \& Hodder 2003, Fox et al. 2015).

Sea wrack (defined here as dead, shore-cast seaweeds and seagrasses) is another example of a marine subsidy that directly and indirectly affects terrestrial ecosystems (Spiller et al. 2010, Del Vecchio et al. 2013). Sea wrack is generally deposited on a shoreline in a strip or in patches that run parallel to the water and mark the high, spring, or storm tide line (Suursaar et al. 2014). While decomposing, wrack that has been washed above the high intertidal zone can act as a direct fertilizer, enriching sand and terrestrial flora (Cardona \& García 2008, Villares et al. 2016). Wrack deposits also provide a nutritionally rich and important food resource for large communities of microbes and semi-terrestrial or terrestrial invertebrate decomposers (Pennings et al. 2000, Ince et al. 2007, Sosik \& Simenstad 2013, Lastra et al. 2014). These can significantly increase both the abundance and diversity of invertebrate communities along shorelines (Dugan et al. 2003, Schlacher et al. 2017). Subsequently, these invertebrate species are ingested by higher trophic level terrestrial consumers. Owing to these interactions, the presence or absence of sea wrack on a shoreline can affect the diversity and abundance of crabs, lizards, birds, and multiple mammalian omnivores (Dugan et al. 2003, Stapp \& Polis 2003, Lewis et al. 2007, Spiller et al. 2010).
As with many marine nutrient subsidies, wrack depositions and accumulations vary temporally. In some locations, wrack biomass accumulations are consistent throughout the year (Barreiro et al. 2011). However, seaweed detritus production may fluctuate due to seasonal senescence, water temperature, wave conditions, shoreline dislodgment, or erosion due to tidal and climate events (Koop \& Field 1980, Stenton-Dozey \& Griffiths 1983, Witman 1987, Seymour et al. 1989, Chapman \& Johnson 1990, Krumhansl \& Scheibling 2011, de Bettignies et al. 2013). Many seaweed species have annual life histories that influence detritus production. For example, bull kelp Nereocystis luetkeana grows from late spring to early fall, then senesces en masse, often dislodging during the first large winter storm (Mann 1973). These seasonal and climatic events can influence the volume and species composition of detrital production, though it is unknown whether this higher availability translates to changes in onshore sea wrack deposition and accumulation. Examining the timing and extent of accumulations may clarify whether sea wrack is ubiquitous temporally or is deposited in seasonal surges, which will help to decipher how resource pulses may affect resource-consumer interactions on islands.

To explore the potential subsidy effect of sea wrack on islands, we first examined the permeability of the coastal boundary by measuring the timing and extent of wrack accumulations on 101 islands within the coastal temperate rainforests of the Central Coast of British Columbia (BC), Canada. We predicted that 3 broad factors may affect macrophyte and macroalgal wrack abundance and distribution: the extent of donor habitats, climate, and physical shoreline characteristics.

The extent and proximity of detrital donor habitats may be a strong indicator of wrack biomass and species composition. On the eastern Pacific coast, vast quantities of sea wrack originate from several donor habitats: intertidal macroalgal beds, subtidal kelp forests, and seagrass meadows. On the Pacific coast of Canada, the dominant canopy-forming kelp species, Macrocystis pyrifera, forms kelp forests that produce up to $900 \mathrm{~g} \mathrm{C} \mathrm{m}^{-2} \mathrm{yr}^{-1}$ (Wilmers et al. 2012), which produce as much as $650 \mathrm{~g} \mathrm{C} \mathrm{m}^{-2}$ of detritus every year (Druehl \& Wheeler 1986). Eelgrass beds of Zostera species are estimated to cover $423 \mathrm{~km}^{2}$ of the coastline of the Central Coast (Reshitnyk et al. 2016), and reach up to $1450 \mathrm{~g} \mathrm{C} \mathrm{m}^{-2} \mathrm{yr}^{-1}$ of primary productivity (Mann 1973), but dislodgment rates have not yet been reported. Aside from these species, the rate of productivity and detrital production is not well 
known for many of the dominant marine macroalgae and seagrasses found throughout the Central Coast. Additionally, little is known about how many of these dislodged kelps and macrophytes are being exported to the open ocean (but see Harrold \& Lisin 1989). Given that BC's convoluted coastline extends for over $29000 \mathrm{~km}$ (including islands) and seaweed communities comprise a lush band that encompasses this complex coastline (Druehl \& Clarkson 2016), there is potential for a large amount of biomass from this band to be washed ashore.

Climate can affect wrack depositions. Factors such as winds and swell, and the interactions among these conditions and the tides, can detach macroalgae and macrophytes from their anchorages (Witman 1987, Seymour et al. 1989, Krumhansl \& Scheibling 2011), creating areas or times with predictable wrack depositions (Oldham et al. 2010, López et al. 2019), especially where there are consistent winds. For instance, increased seagrass deposits in the northwest Mediterranean are attributed to strong wind events (Jiménez et al. 2017), higher than normal tides have increased wrack accumulation along Estonian shorelines (Suursaar et al. 2014), and on the Pacific coastline of the USA, wave events caused by swell increased wrack accumulations (Reimer 2014). Additionally, storms can facilitate sporadic long-distance kelp dispersal events, disrupting patterns of connectivity across ecosystem boundaries (Waters et al. 2018).

The third broad factor potentially affecting sea wrack accumulation and retention is a site's physical shoreline characteristics, which are: slope, substrate, aspect, width, and wave exposure. Interactions between beach length and exposure to waves that resulted in greater edge exposures to donor habitats (similar to the large perimeter to area ratios seen on small islands) increased wrack accruals in Spain (Barreiro et al. 2011). Along the coastlines of Vancouver Island, BC, shores composed of cobble substrates retained significantly more wrack than those composed of sand or gravel, as the spaces between cobbles trapped large wrack particles and retained them despite tidal and wave forces (Orr et al. 2005). In California, sloped beaches were positively correlated with the retention of Phyllospadix spp., suggesting that steeper beaches can retain greater amounts of specific wrack species when high tides deposit wrack high upon the shoreline (Liebowitz et al. 2016), presumably in part due to the buoyancy of a species (Oldham 2014).

Although globally sea wrack as a vector of marine to terrestrial nutrient transfer is a well-studied phenomenon, little research exists on the mechanisms of wrack deposition and accumulations on island shorelines across extended spatial and temporal scales. In this study, we aimed to determine the drivers of spatial and temporal wrack variability across large spatial and temporal scales by distinguishing when and where sea wrack is most likely to accumulate along coastlines by asking the following questions: (1) What are the biophysical and environmental variables that best explain patterns in wrack accumulations onshore? (2) What are the seasonal changes in accumulated wrack biomass and species composition?

\section{MATERIALS AND METHODS}

\subsection{Study region}

The Central Coast of $\mathrm{BC}$ encompasses the region between the northern tip of Vancouver Island $\left(50.7865^{\circ} \mathrm{N}, 128.2324^{\circ} \mathrm{W}\right)$ and the southern tip of Haida Gwaii $\left(51.8711^{\circ} \mathrm{N}, 131.0010^{\circ} \mathrm{W}\right)$. The study area spanned $2000 \mathrm{~km}^{2}$ within the Central Coast region (Fig. 1), which contains $\sim 1500$ islands. This region is located within the very wet hypermaritime subzone of the Coastal Western Hemlock biogeoclimatic classification (Meidinger \& Pojar 1991), which is characterized by cool summers (mean warmest month $14.0^{\circ} \mathrm{C}$ ), warm winters (mean coldest month $2.3^{\circ} \mathrm{C}$ ), and large amounts of precipitation (mean annual precipitation $>3000 \mathrm{~mm}$ ) (Meidinger \& Pojar 1991). The sea surface ocean temperatures range from a mean low of $7^{\circ} \mathrm{C}$ in March to a mean high of $15^{\circ} \mathrm{C}$ in August (Jackson et al. 2015). Tides in the region fluctuate from 3 to $5 \mathrm{~m}$ and are semidiurnal (Thomson 1981). Field work was conducted out of the Hakai Institute on Calvert Island, BC, within the Hakai Lúxvbálís Conservancy, and in the Penrose Island Marine Provincial Park area under a longterm operation BC Parks Use Permit No. 107190. All research was conducted within the territories and with permission of the Heiltsuk and Wuikinuxv First Nations.

\subsection{Spatial surveys}

\subsubsection{Island selection}

We selected 101 islands to represent a range of island characteristics and used cluster analysis to provide a method of data reduction that still ensured a range of island characteristics were sampled (Hargrove \& Hoffman 2004). Five biogeographical de- 

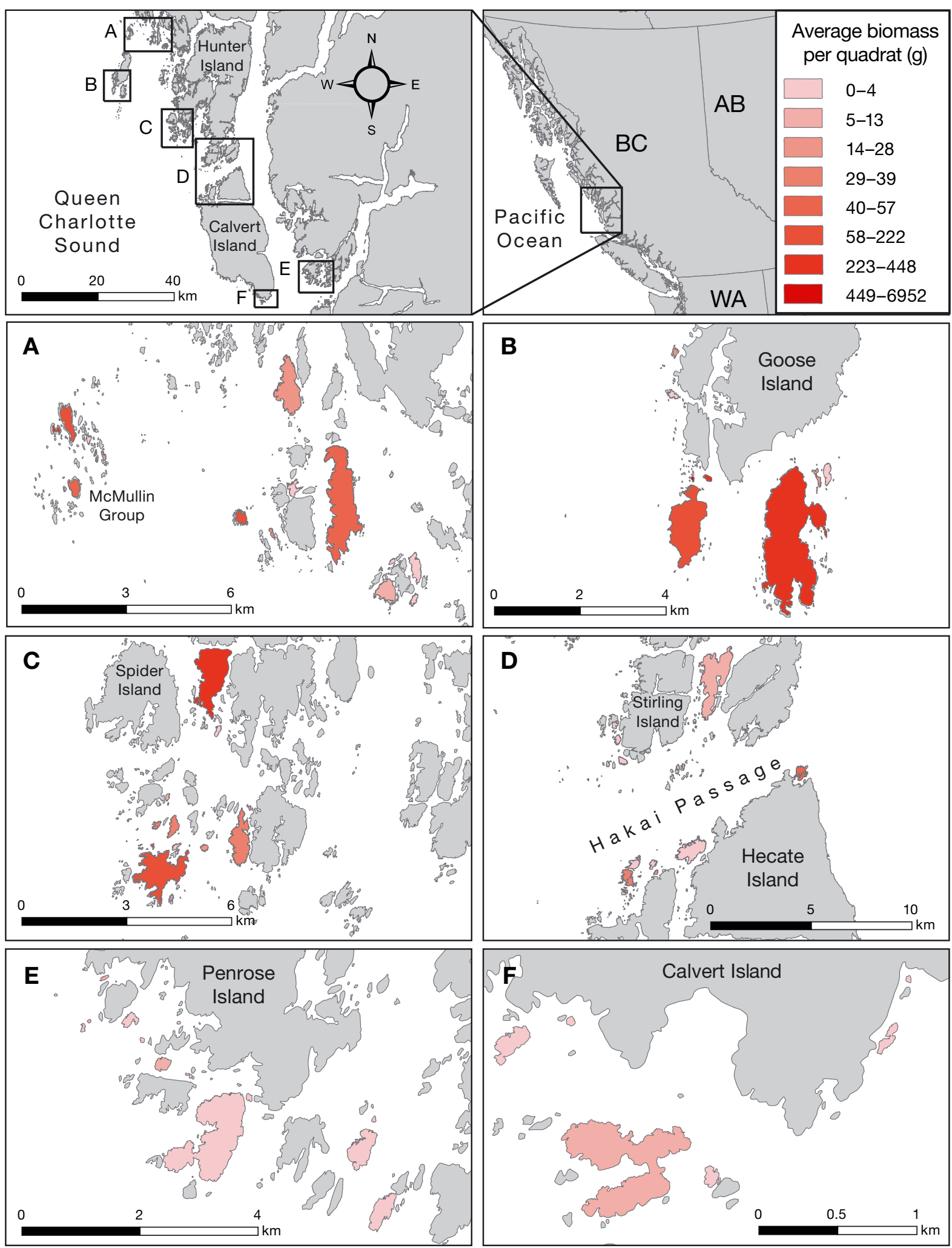

Fig. 1. Central Coast of British Columbia (BC), Canada (top right; WA: Washington State, AB: Alberta). The study region and location of nodes of study islands as selected by cluster analysis (top left). All study islands are colored in red shades according to their average biomass per quadrat (g) dry biomass accumulations. (A) McMullin, Tribal, and Admiral nodes (52.0457 ${ }^{\circ} \mathrm{N}$, $\left.128.3563^{\circ} \mathrm{W}\right)$; (B) Goose node $\left(51.9291^{\circ} \mathrm{N}, 128.4524^{\circ} \mathrm{W}\right)$; (C) Triquet node $\left(51.8256^{\circ} \mathrm{N}, 128.2132^{\circ} \mathrm{W}\right)$; (D) Calvert and Stirling nodes $\left(51.7425^{\circ} \mathrm{N}, 128.0576^{\circ} \mathrm{W}\right) ;(\mathrm{E})$ Penrose node $\left(51.4632^{\circ} \mathrm{N}, 127.7247^{\circ} \mathrm{W}\right) ;$ and $(\mathrm{F})$ South Calvert node $\left(51.4250^{\circ} \mathrm{N}\right.$, 


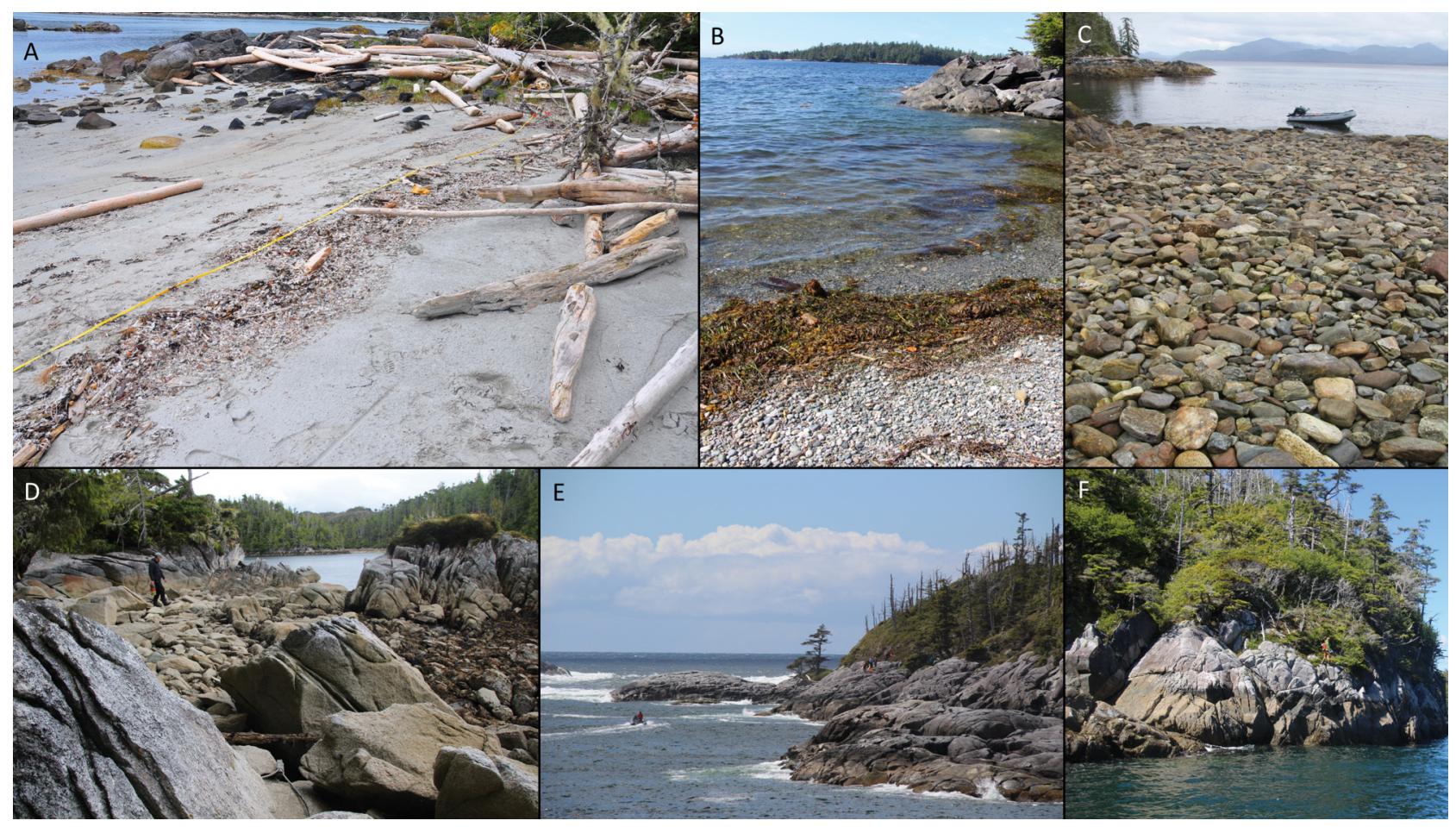

Fig. 2. Examples of the different types of shoreline substrates commonly found on the west coast of British Columbia: (A) sand on island GS05 $\left(51.9271^{\circ} \mathrm{N}, 128.4691^{\circ} \mathrm{W}\right)$, (B) gravel on island GS03 $\left(51.9170^{\circ} \mathrm{N}, 128.4763^{\circ} \mathrm{W}\right)$, (C) cobble on island CV17 $\left(51.7306^{\circ} \mathrm{N}, 128.0012^{\circ} \mathrm{W}\right),(\mathrm{D})$ boulder on island ST14 $\left(51.7729^{\circ} \mathrm{N}, 128.0626^{\circ} \mathrm{W}\right)$, (E) rock on island $\mathrm{SC} 01\left(51.4160^{\circ} \mathrm{N}\right.$, $\left.127.9203^{\circ} \mathrm{W}\right)$, and $(\mathrm{F})$ rock on island ST10 $\left(51.7463^{\circ} \mathrm{N}, 128.1323^{\circ} \mathrm{W}\right)$. Refer to Supplement Table S3 for island node and number abbreviations

scriptors (distance from mainland, area, normalized perimeter to island ratio, exposure, neighboring land) for all islands within the study region $(\mathrm{n}=1470)$ were derived (see Table S1 in the Supplement at www.int-res.com/articles/suppl/m635p037_supp. pdf), and additional biogeographical characteristics were extrapolated from the BC ShoreZone dataset (Howes et al. 1994). The results of cluster analysis identified several nodes (Table S2) where islands with different biogeographical descriptors were located within close proximity to each other. Within a node, islands were selected to maximize variation across a range of island sizes and shoreline structure. The final dataset consisted of 101 islands within 9 nodes (Fig. 1, Table S3).

\subsubsection{Wrack biomass and composition measurements}

During the spring/summer season (May-August) of 2015-2017, we visited each island one time throughout the 3 yr period. During a visit, we conducted 4 surveys per island, one at each of the predetermined coordinates representing the furthest north, east, south, and west aspect of each island. Depending on the availability of substrate, additional surveys were conducted on islands that had shorelines with either a sand, gravel, cobble, or boulder substrate (Fig. 2). This allowed us to examine substrate effects on wrack retention. Therefore, each island had a minimum of 4 to a maximum of 10 survey sites resulting in a total of 455 sites in the study area. Each survey entailed one $20 \mathrm{~m}$ transect, centered on the most recent high tide wrack line (which ran roughly parallel to the waterline), and beginning at the pre-determined cardinal direction coordinates.

We randomly sampled $1 \mathrm{~m}^{2}(\mathrm{n}=3)$ quadrats along each transect line. Within each quadrat, we identified and sorted all wrack either to the functional algal group (as per Steneck \& Dethier 1994), genus, or species level and then weighed all samples. Wrack that was unidentifiable was categorized as such and weighed. Wrack that was partially buried but still had a portion visible was uncovered, rinsed or wiped of sand, sorted, and weighed. Wrack was weighed with either a small scale with precision of $\pm 2 \mathrm{~g}$ or a hanging spring scale with precision of $\pm 1 \mathrm{~kg}$ at- 
tached to a tarp. Following methods outlined by Wickham et al. (2019), we collected subsamples from 12 of the most common seaweed species to derive a correction factor for wet to dry weight conversions. All biomass results for both spatial and temporal data are reported in dry estimates.

\subsubsection{Biophysical and environmental measurements}

To determine the drivers of wrack accumulation, we included 10 biophysical and environmental measurements as variables in our analysis (wind direction, wind speed, wave height, wave period, high tide, shoreline slope, shoreline width, shoreline wave exposure, shoreline substrate, and extent of nearby donor habitat; Table 1).

To determine the relative contribution of donor habitat in explaining wrack biomass measurements, we first determined each site's proximity to a wrack source. We identified the 3 main wrack donor habitats within our study area: (1) kelp forests as donors of Macrocystis pyrifera and Nereocystis luetkeana,
(2) eelgrass beds as donors of Zostera marina, and (3) rocky intertidal shorelines as donors of Fucus distichus. We analyzed remotely piloted aerial system (RPAS)-based digital photogrammetry and WorldView-2 multispectral satellite imagery in ArcGIS and estimated the extent of all donor habitats, then summed these estimates. Kelps such as $M$. pyrifera commonly wash ashore within a $5 \mathrm{~km}$ radius of their detachment sites (Dugan \& Miller 2019), so we positioned a set of radii around each survey site (length of radii $=50,100$, and $500 \mathrm{~m}$, and $1,2,3,4,5$, and $7.5 \mathrm{~km}$ ) and analyzed the strength of the relationship between the summed area of donor habitat and the onshore biomass of kelp/eelgrass/F distichus using Spearman's correlation analysis for non-normally distributed data (Fig. S1). Following methods established by Liebowitz et al. (2016), the extent of donor habitat within the radius with the strongest relationship (from our analysis: $2 \mathrm{~km}$ ) was used for subsequent analysis.

Climate variables such as hourly wind direction, wind speed, wave height, and wave period measurements for the day of a site visit were accessed from Environment Canada West Sea Otter Buoy archives

Table 1. Biophysical and environmental variables used as predictors in the candidate models. VC: variable categories; variables that are continuous are listed as 'na'

\begin{tabular}{|c|c|c|c|c|}
\hline Parameter & Variable & $\mathrm{VC}$ & Source & Description \\
\hline $\begin{array}{l}\text { Donor } \\
\text { habitat }\end{array}$ & $\begin{array}{l}\text { Donor } \\
\text { habitat }\end{array}$ & na & $\begin{array}{l}\text { WorldView-2 and } \\
\text { RPAS imagery }\end{array}$ & $\begin{array}{l}\text { Extent of summed Zostera marina, Fucus distichus, } \\
\text { Nereocystis luetkeana, and Macrocystis pyrifera } \\
\text { habitat visible within } 2 \mathrm{~km} \text { of a survey site }\left(\mathrm{m}^{2}\right)\end{array}$ \\
\hline \multirow[t]{4}{*}{ Climate } & $\begin{array}{l}\text { Wind } \\
\text { direction }\end{array}$ & na & $\begin{array}{l}\text { Environment } \\
\text { Canada }\end{array}$ & Direction from which the wind is blowing ( ${ }^{\circ}$ True) \\
\hline & $\begin{array}{l}\text { Wave } \\
\text { height }\end{array}$ & na & $\begin{array}{l}\text { Environment } \\
\text { Canada }\end{array}$ & Wave height as reported by the buoy (m) \\
\hline & $\begin{array}{l}\text { Wave } \\
\text { period }\end{array}$ & na & $\begin{array}{l}\text { Environment } \\
\text { Canada }\end{array}$ & Wave peak period as reported by the buoy (s) \\
\hline & High tide & na & $\begin{array}{l}\text { Fisheries and } \\
\text { Oceans Canada }\end{array}$ & $\begin{array}{l}\text { Predicted high water associated with vertical } \\
\text { movement of tide }(\mathrm{m})\end{array}$ \\
\hline \multirow[t]{5}{*}{ Site } & Aspect & na & $\begin{array}{l}\text { WorldView-2 and } \\
\text { RPAS imagery }\end{array}$ & $\begin{array}{l}\text { Mean value of } 5 \text { measurements taken at } 5 \mathrm{~m} \\
\text { intervals for } 20 \mathrm{~m}\left(^{\circ}\right)\end{array}$ \\
\hline & Slope & na & $\begin{array}{l}\text { WorldView-2 and } \\
\text { RPAS imagery }\end{array}$ & $\begin{array}{l}\text { Mean value of } 5 \text { measurements taken at } 5 \mathrm{~m} \\
\text { intervals for } 20 \mathrm{~m}\left(^{\circ}\right)\end{array}$ \\
\hline & Substrate & $\begin{array}{l}\text { Sand, gravel, cobble, } \\
\text { boulder, rock }\end{array}$ & Recorded at site & Determined via Wentworth scale of grain size \\
\hline & Width & na & $\begin{array}{l}\text { WorldView-2 and } \\
\text { RPAS imagery }\end{array}$ & $\begin{array}{l}\text { Mean value of } 5 \text { measurements taken at } 5 \mathrm{~m} \\
\text { intervals for } 20 \mathrm{~m} \mathrm{(m)}\end{array}$ \\
\hline & $\begin{array}{l}\text { Wave } \\
\text { exposure }\end{array}$ & $\begin{array}{l}\text { Very protected, } \\
\text { protected, semi- } \\
\text { protected, semi- } \\
\text { exposed, exposed, } \\
\text { very exposed }\end{array}$ & Recorded at site & Classified via biobands (Howes et al. 1994) \\
\hline
\end{tabular}


(West Sea Otter Archive Plot ${ }^{\mathbf{1}}$ ). Data from $6 \mathrm{~h}$ prior to a site visit until the hour of the site visit were averaged (the amount of time for 1 tidal cycle; Fig. S2). We included tide as a climate variable because of the potential for wind and waves to interact with tidal conditions.

We collected data pertaining to a site's physical characteristics following protocols outlined in the ShoreZone Coastal Habitat Mapping Protocol (Harper \& Morris 2014). This protocol describes methods to catalog geomorphic and biological coastal features of the Pacific Northwest (including BC, Alaska, Washington, and Oregon). Site data collected included shoreline slope, aspect, substrate, width, and biobands (patterns of identifiable biota observable in the intertidal and supralittoral zone) (Howes et al. 1994). Biobands were used to classify the wave exposure of a site as per the ShoreZone Mapping Protocol (Harper \& Morris 2014). Substrate categories were adapted from the Wentworth scale of grain size and included sand, gravel, cobble, boulder, and rock (Wentworth 1922). Shoreline slope, aspect, and width measurements were obtained from RPASderived imagery and elevation models, which were produced at $10 \mathrm{~cm}$ ground resolution and processed according to the methods outlined by Nijland et al. (2017). This dataset generated slope, aspect, and width measurements at every $5 \mathrm{~m}$ along every island's shoreline, which we averaged for each $20 \mathrm{~m}$ transect.

\subsection{Temporal surveys}

\subsubsection{Site selection}

We chose 3 easily accessible sites for temporal surveys because winter wind, storms, and swells can limit boat access. These included North Beach $\left(51.6628^{\circ} \mathrm{N}\right.$, $\left.128.1401^{\circ} \mathrm{W}\right)$, West Beach $\left(51.6558^{\circ} \mathrm{N}, 128.120^{\circ} \mathrm{W}\right)$, and Fourth Beach $\left(51.6431^{\circ} \mathrm{N}, 128.1510^{\circ} \mathrm{W}\right)$ on Calvert Island, all of which are classified as flat $\left(<5^{\circ}\right)$, sandy, semi-exposed shorelines (Howes et al. 1994). Sites with consistent biophysical characteristics were chosen to best gauge temporal rather than biophysical effects. Surveys were conducted during the lowest tide $(<1.0 \mathrm{~m})$ once every 2 mo starting in July 2016 and ending in April 2017, with one 3 mo period between the November 2016 and February 2017 survey dates.

$\underline{1}_{\text {http://www.meds-sdmm.dfo-mpo.gc.ca/isdm-gdsi/waves- }}$ vagues/index-eng.htm

\subsubsection{Wrack biomass and composition measurements}

To establish a finer-scaled resolution of the shift in accumulated wrack biomass and species composition throughout a seasonal interval, we visited each site twice ( 2 d apart) every 2 mo and performed 6 transects per visit $(n=12)$. The terrestrial edges of each site were divided into $100 \mathrm{~m}$ intervals, and 6 transect locations were randomly generated. One transect per $100 \mathrm{~m}$ was completed to avoid overlap along the beach. Transects ran perpendicular to the water, starting at the terrestrial edge and marked permanently with flagging tape. A compass bearing was measured along the perpendicular direction, and this bearing was followed for each survey to create a repeatable transect. We collected wrack starting at the daily high tide wrack line and ending at the lowest water level experienced during the daily low tide. All wrack within $0.5 \mathrm{~m}$ of either side of the transect line was collected, identified, and weighed. Collected and weighed wrack was placed far above the highest tidal line to prevent it from being redeposited in the transect during the next survey ( $2 \mathrm{~d}$ following). A wet-to-dry mass calibration was established using previously collected data (Wickham et al. 2019).

\subsection{Statistical analysis}

\subsubsection{Spatial surveys}

All analyses were performed in $\mathrm{R}$ version 3.5.1 ( $\mathrm{R}$ Core Team 2018). To test the variability in wrack species composition among nodes, we analyzed the relative biomass accumulation of each wrack taxon per site using analysis of similarity (ANOSIM) (Clarke 1993). ANOSIM routines are based on a Bray-Curtis dissimilarity matrix of species occurrences using the species' logged dry biomass data. A similarity percentage (SIMPER) routine was performed to identify the species with the highest contribution to the similarity/dissimilarity of each node. All data were analyzed using the 'vegan' package in R (Oksanen et al. 2017). To determine which nodes accumulated the most wrack, dry biomass per site was compared using ANOVA, with node $(\mathrm{n}=9)$ as a fixed factor and island $(\mathrm{n}=101)$ as a random variable using the 'ImerTest' package in R (Kuznetsova et al. 2017).

We used a modeling approach to investigate how our potential explanatory variables predicted the presence and biomass of wrack across our study sites. Given that our dataset was heavily inflated with 
zeros (i.e. no wrack found in a quadrat), we separated the data into 2 datasets (a presence/absence dataset and a biomass dataset) and used hurdle modeling (Zuur et al. 2009). This required 2 steps. First, the data were considered as zero or non-zero to capture the probability of wrack presence on a beach during the surveys. Second, all zero data points were removed and a normally distributed dataset was created that captured wrack biomass accumulations on a beach once wrack was present.

Prior to modeling, the response variable (dry biomass) was log-transformed to normalize distribution. Periodic data (wind direction and aspect variables) were multiplied by sine and cosine to account for cyclical values (Roberts 1986). Wind speed and wave height were correlated and wind speed was subsequently removed because wave height provides a more direct measure of the process we intended to investigate. High and low tides were correlated, so we removed low tide, given our primary interest in understanding the ability of a high tide to transfer wrack ashore. Continuous predictor variables (wind speed, wave period, wave height, high tide, slope, width, and extent of donor habitat) were standardized by subtracting the mean and dividing by the standard deviation.

To analyze the presence/absence dataset, we used a generalized linear model (GLM) with binomial distribution (Zuur et al. 2009). To analyze the biomass data set, we used a linear mixed effect model with Gaussian distribution and month and year as random effects and our 10 biophysical predictor variables for fixed effects (as described in Table 1) using the $\mathrm{R}$ package 'nlme' (Pinheiro et al. 2017). We ranked the multiple candidate models generated for each dataset using Akaike's information criterion (AIC) (Burnham \& Anderson 1998). We developed multiple candidate models a priori (Tables 2 \& 3) for both datasets. All models within 4 points of the lowest AIC

Table 2. Akaike's information criterion (AIC) values from candidate models to predict sea wrack presence/absence. $\Delta$ AIC: difference between the current and best model; $\mathrm{AIC}_{\mathrm{w}}$ : Akaike weight; $\mathrm{DE}$ : proportion of deviance explained by the model; $\left({ }^{*}\right)$ denotes interaction terms. Best performing models are in bold text

\begin{tabular}{|c|c|c|c|c|c|}
\hline Parameters & Variables & AIC & $\Delta \mathrm{AIC}$ & $\mathrm{AIC}_{\mathrm{W}}$ & $\mathrm{DE}$ \\
\hline $\begin{array}{l}\text { Site + Donor } \\
\text { Habitat }\end{array}$ & $\begin{array}{c}\text { Aspect }+ \text { Slope }+ \text { Substrate }+ \text { Width }+ \text { Wave Exposure }+ \\
\text { Donor Habitat }\end{array}$ & 236.59 & $\mathbf{0}$ & 0.50 & 0.64 \\
\hline $\begin{array}{l}\text { Site }+ \text { Climate }^{*}+ \\
\text { Donor Habitat }\end{array}$ & $\begin{array}{c}\text { Aspect }+ \text { Slope }+ \text { Substrate }+ \text { Width }+ \text { Wave Exposure }+ \text { Wind } \\
\text { Direction } \times \text { Wave Height }+ \text { Wave Period }+ \text { High Tide }+ \text { Donor Habitat }\end{array}$ & 237.01 & 0.42 & 0.41 & 0.66 \\
\hline $\begin{array}{l}\text { Site + Climate + } \\
\text { Donor Habitat }\end{array}$ & $\begin{array}{c}\text { Aspect + Slope + Substrate + Width + Wave Exposure + Wind } \\
\text { Direction + Wave Height }+ \text { Wave Period + High Tide + Donor Habitat }\end{array}$ & 240.05 & 3.46 & 0.09 & 0.65 \\
\hline Site & Aspect + Slope + Substrate + Width + Wave Exposure & 281.01 & 44.42 & 0 & 0.56 \\
\hline Site + Climate & $\begin{array}{c}\text { Aspect }+ \text { Slope + Substrate + Width + Wave Exposure + } \\
\text { Wind Direction + Wave Height }+ \text { Wave Period + High Tide }\end{array}$ & 282.73 & 46.14 & 0 & 0.58 \\
\hline $\begin{array}{l}\text { Site }^{*}+\text { Climate }^{*}+ \\
\text { Site } \times \text { Climate }+ \\
\text { Donor Habitat }\end{array}$ & $\begin{array}{c}\text { Aspect } \times \text { Wind Direction }+ \text { Slope } \times \text { Substrate }+ \text { Width }+ \\
\text { Wave Exposure }+ \text { Wind Direction } \times \text { Wave Height }+ \text { Wave Period }+ \\
\text { High Tide }+ \text { Donor Habitat }\end{array}$ & 361.97 & 125.38 & 0 & 0.44 \\
\hline $\begin{array}{l}\text { Site }^{*}+\text { Climate }+ \\
\text { Donor Habitat }\end{array}$ & $\begin{array}{c}\text { Aspect }+ \text { Slope } \times \text { Substrate }+ \text { Width }+ \text { Wave Exposure }+ \text { Wave Height } \\
+ \text { High Tide }+ \text { Donor Habitat }\end{array}$ & 366.34 & 129.75 & 0 & 0.44 \\
\hline $\begin{array}{l}\text { Site }^{*}+\text { Donor } \\
\text { Habitat }\end{array}$ & Aspect + Slope $\times$ Substrate + Width + Wave Exposure + Donor Habitat & 369.35 & 132.76 & 0 & 0.41 \\
\hline Site $^{*}+$ Climate $^{*}$ & $\begin{array}{c}\text { Aspect }+ \text { Slope } \times \text { Substrate }+ \text { Width }+ \text { Wave Exposure }+ \\
\text { Wind Direction } \times \text { Wave Height }+ \text { High Tide }\end{array}$ & 397.61 & 161.02 & 0 & 0.38 \\
\hline Site $^{*}$ & Aspect + Slope $\times$ Substrate + Width + Wave Exposure & 404.04 & 167.45 & 0 & 0.34 \\
\hline $\begin{array}{l}\text { Climate }^{*}+\text { Donor } \\
\text { Habitat }\end{array}$ & $\begin{array}{c}\text { Wind Direction } \times \text { Wave Height }+ \text { Wave Period }+ \text { High Tide }+ \\
\text { Donor Habitat }\end{array}$ & 477.52 & 240.93 & 0 & 0.21 \\
\hline $\begin{array}{l}\text { Climate + Donor } \\
\text { Habitat }\end{array}$ & $\begin{array}{c}\text { Wind Direction + Wave Height }+ \text { Wave Period + High Tide + } \\
\text { Donor Habitat }\end{array}$ & 499.96 & 263.37 & 0 & 0.16 \\
\hline Donor Habitat & Donor Habitat & 508.39 & 271.80 & 0 & 0.13 \\
\hline Climate $^{*}$ & Wind Direction $\times$ Wave Height + Wave Period + High Tide & 570.33 & 333.74 & 0 & 0.03 \\
\hline Climate & Wind Direction + Wave Height + Wave Period + High Tide & 570.79 & 334.20 & 0 & 0.03 \\
\hline
\end{tabular}


Table 3. Akaike's Information criterion (AIC) values from candidate models to predict accumulated sea wrack biomass. AIC: AIC score; $\triangle \mathrm{AIC}$ : difference between the current and best model; $\mathrm{AIC}_{\mathrm{w}}$ : Akaike weight; $\left({ }^{*}\right)$ denotes interaction terms. Best performing models are in bold text

\begin{tabular}{|c|c|c|c|c|}
\hline Parameters & Variables & AIC & $\Delta \mathrm{AIC}$ & $\mathrm{AIC}_{\mathrm{W}}$ \\
\hline Site $^{*}$ & Aspect + Slope $\times$ Substrate + Width + Wave Exposure & 732.68 & $\mathbf{0}$ & 0.54 \\
\hline Site $^{*}+$ Donor Habitat & Aspect + Slope + Substrate + Width + Wave Exposure + Donor Habitat & 734.68 & 2 & 0.20 \\
\hline Site & Aspect + Slope + Substrate + Width + Wave Exposure & 735.99 & 3.31 & 0.10 \\
\hline Site $^{*}+$ Climate ${ }^{*}$ & $\begin{array}{c}\text { Aspect }+ \text { Slope } \times \text { Substrate }+ \text { Width }+ \text { Wave Exposure }+ \text { Wind Direction } \times \\
\text { Wave Height }+ \text { Wave Period }+ \text { High Tide }\end{array}$ & 737.37 & 4.69 & 0.05 \\
\hline Site + Donor Habitat & Aspect + Slope + Substrate + Width + Wave Exposure + Donor Habitat & 737.86 & 5.18 & 0.04 \\
\hline Site + Climate & $\begin{array}{c}\text { Aspect }+ \text { Slope }+ \text { Substrate }+ \text { Width }+ \text { Wave Exposure }+ \text { Wind Direction }+ \\
\text { Wave Height }+ \text { Wave Period }+ \text { High Tide }\end{array}$ & 739.47 & 6.79 & 0.02 \\
\hline $\begin{array}{l}\text { Site }{ }^{*}+\text { Climate }+ \\
\text { Donor Habitat }\end{array}$ & $\begin{array}{c}\text { Aspect }+ \text { Slope } \times \text { Substrate }+ \text { Width }+ \text { Wave Exposure }+ \text { Wind Direction }+ \\
\text { Wave Height }+ \text { Wave Period }+ \text { High Tide }\end{array}$ & 739.77 & 7.09 & 0.02 \\
\hline $\begin{array}{l}\text { Site }^{*}+\text { Climate }^{*}+ \\
\text { Site } \times \text { Climate }+ \\
\text { Donor Habitat }\end{array}$ & $\begin{array}{c}\text { Aspect }+ \text { Slope } \times \text { Substrate }+ \text { Width }+ \text { Wave Exposure }+ \text { Wind Direction } \times \\
\text { Wave Height }+ \text { Wave Period }+ \text { High Tide }+ \text { Wind Direction } \times \text { Aspect }+ \\
\text { Donor Habitat }\end{array}$ & 741.26 & 8.58 & 0.01 \\
\hline $\begin{array}{l}\text { Site }+ \text { Climate }+ \\
\text { Donor Habitat }\end{array}$ & $\begin{array}{c}\text { Aspect }+ \text { Slope }+ \text { Substrate }+ \text { Width }+ \text { Wave Exposure }+ \text { Wind Direction }+ \\
\text { Wave Height }+ \text { Wave Period }+ \text { High Tide }+ \text { Donor Habitat }\end{array}$ & 741.47 & 8.79 & 0.01 \\
\hline $\begin{array}{l}\text { Site }+ \text { Climate }{ }^{*}+ \\
\text { Donor Habitat }\end{array}$ & $\begin{array}{c}\text { Aspect }+ \text { Slope }+ \text { Substrate }+ \text { Width }+ \text { Wave Exposure }+ \text { Wind Direction } \times \\
\text { Wave Height }+ \text { Wave Period }+ \text { High Tide }+ \text { Donor Habitat }\end{array}$ & 741.69 & 9.01 & 0.01 \\
\hline Donor Habitat & Donor Habitat & 743.24 & 10.56 & 0 \\
\hline Climate & Wind Direction + Wave Height + Wave Period + High Tide & 744.22 & 11.54 & 0 \\
\hline Climate* & Wind Direction $\times$ Wave Height + Wave Period + High Tide & 745.92 & 13.24 & 0 \\
\hline $\begin{array}{l}\text { Climate + Donor } \\
\text { Habitat }\end{array}$ & $\begin{array}{c}\text { Wind Direction }+ \text { Wave Height }+ \text { Wave Period }+ \text { High Tide }+ \text { Donor } \\
\text { Habitat }\end{array}$ & 745.95 & 13.27 & 0 \\
\hline $\begin{array}{l}\text { Climate }^{*}+\text { Donor } \\
\text { Habitat }\end{array}$ & $\begin{array}{c}\text { Wind Direction } \times \text { Wave Height }+ \text { Wave Period }+ \text { High Tide }+ \\
\text { Donor Habitat }\end{array}$ & 747.84 & 15.16 & 0 \\
\hline
\end{tabular}

value were considered to have similar levels of support. From the top models, we determined which option best explained the data by calculating the Akaike weight for each model and the proportion of deviance being explained for the presence/absence model (Tables 2 \& 3) (Burnham et al. 2011).

For both the presence/absence and the biomass datasets, we checked the models for independence and spatial correlation by examining the residuals of each top model for signals that we violated independence (Fig. S3) and none were detected. Wrack accumulation is understood to be determined by biophysical forces (represented by our predictor variables), not the influence of latitude or longitude (Barreiro et al. 2011). However, for both the presence/ absence and the biomass dataset, we examined the residuals of each top model for signals that we violated assumptions of spatial independence in the linear model. We plotted residuals against latitude, longitude, and island node and found no patterns of concern. We also mapped residuals against their spatial coordinates using the package 'gstat' in R (Pebesma 2004, Graler et al. 2016) to check for any patterns that may indicate spatial correlation issues not captured by plots of latitude or longitude individually (Figs. S4-S7).

\subsubsection{Temporal surveys}

Dry wrack biomass was log transformed and compared across months $(\mathrm{n}=5)$ and sites $(\mathrm{n}=3)$ using ANOVA, and significant differences in biomass accumulations among months and sites were explored via Tukey's HSD test. To test the variability in wrack species composition and biomass accumulation through time, we analyzed the relative biomass accumulation of each wrack taxon per month and per site using ANOSIM (Clarke 1993). Non-metric multidimensional scaling using Bray-Curtis dissimilarity 
matrix techniques was also used to assess whether composition changed with seasons or between sites. A SIMPER routine was performed to identify the species with the highest contribution to the similarity/ dissimilarity of each month or site. The ShannonWiener diversity index was used to explore species diversity in the summer (June, July, September) compared to the winter (November, February, April).

\section{RESULTS}

\subsection{Spatial surveys}

A total of 52 genus, functional group, or species representatives were recorded throughout the study region (Table S4). Calvert node had the highest number of species $(n=35)$ and Stirling node had the lowest ( $\mathrm{n}=8$, Fig. 3). Six species contributed to $84 \%$ of the total biomass accumulations: Zostera marina (40\% of total biomass), Fucus distichus (26\%), Pterygophora californica (10\%), Macrocystis pyrifera (4\%), and Nereocystis luetkeana and Phyllospadix spp. (each contributing $2 \%$ to total biomass) (Table S4). The other 46 species each contributed $1 \%$ or less of total accumulated biomass (Table S4). Species composition was dissimilar among nodes (ANOSIM; factor = node,

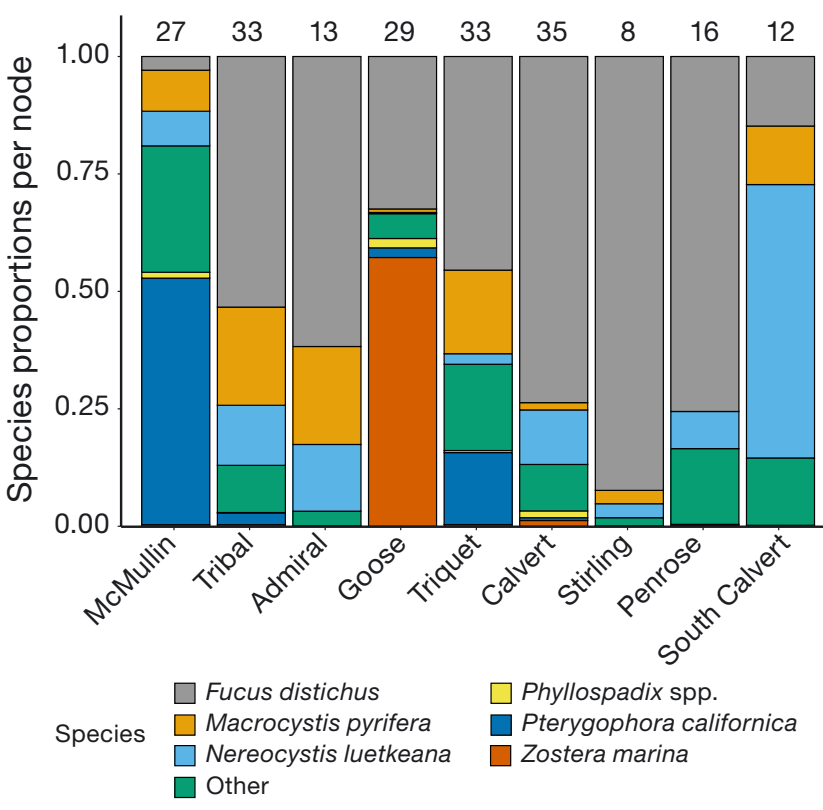

Fig. 3. Proportions for each node of the 6 dominant algal species observed throughout the study area. 'Other' is the combined total of all other species recorded in that node. Proportions are calculated from summed dry biomass. Total number of species of seaweeds recorded in the wrack deposits for each node is displayed above the bar
$\mathrm{R}=0.08, \mathrm{p}<0.02$, Fig. 3; Fig. S8). The top contributors to the dissimilarities among nodes were Zostera spp., $F$. distichus, and P. californica (SIMPER; Zostera spp. average dissimilarity $=69 \%, F$. distichus $=49 \%, P$. californica $=43 \%$ ). All SIMPER results for the cumulative contribution of the most influential species can be found in Fig. S9. Driving these dissimilarities are species that appeared dominant in certain nodes: $P$. californica was abundant in the McMullin node, $Z$. marina in the Goose node, N. luetkeana in the South Calvert node, and F. distichus in all nodes except McMullin (Fig. 3).

Accumulated wrack biomass varied widely across the study region (Fig. 1A-F), ranging from $0 \mathrm{~g} \mathrm{~m}^{-2}$ on many islands to a mean of $6952 \pm 4325$ (SD) $\mathrm{g} \mathrm{m}^{-2}$ at one small island in Goose node. Average wrack accumulations per site did not differ among nodes (ANOVA; $F=0.42, \mathrm{p}=0.9$ ).

In tests for the presence/absence of wrack, the top model was composed of 2 parameter groups: site and the extent of donor habitat (Table 2). This model indicated that the combination of aspect, slope, width, wave exposure, substrate, and extent of donor habitat best predicted whether a site would have wrack present (Table 2). Examining the relative influence of each factor in the top model, substrate, extent of donor habitat, and slope had significant associations (Table 4). Of the 5 substrate types (sand, gravel, cobble, boulder, and rock), rock had a strong negative

Table 4. Coefficient estimate, standard error (SE), and pvalue for each term in the top model (see Table 2) predicting wrack presence/absence, as determined by the lowest AIC and highest $\mathrm{AIC}_{\mathrm{w}}$ scores. Coefficient estimate is standardized for continuous predictor variables (shoreline width, wave period, and donor habitat). The first (alphabetical) term for categorical variables (substrate: boulder and wave exposure: exposed) is the reference/baseline for that category. Significant terms are in bold text

\begin{tabular}{|lccc}
\hline Variable & Estimate & SE & $\mathrm{p}$ \\
\hline Sine aspect & 0.24 & 0.28 & 0.4 \\
Cosine aspect & -0.44 & 0.27 & 0.1 \\
Shoreline slope & $\mathbf{- 0 . 8 3}$ & $\mathbf{0 . 3 2}$ & $\mathbf{< 0 . 0 1}$ \\
Shoreline width & 0.57 & 0.32 & 0.8 \\
Wave exposure: very protected & 1.85 & 1.03 & 0.07 \\
Wave exposure: protected & 1.45 & 0.79 & 0.06 \\
Wave exposure: semi-protected & 0.96 & 0.82 & 0.2 \\
Wave exposure: semi-exposed & 0.49 & 0.80 & 0.5 \\
Wave exposure: very exposed & -0.28 & 0.98 & 0.8 \\
Substrate: sand & 14.5 & 1022.67 & 1 \\
Substrate: gravel & -0.29 & 1.40 & 0.8 \\
Substrate: cobble & 0.82 & 1.30 & 0.5 \\
Substrate: rock & $\mathbf{- 4 . 8 4}$ & $\mathbf{0 . 6 9}$ & $\mathbf{< 0 . 0 1}$ \\
Donor habitat & $\mathbf{1 . 4 2}$ & $\mathbf{0 . 2 6}$ & $<\mathbf{0 . 0 1}$ \\
& & & \\
\hline
\end{tabular}



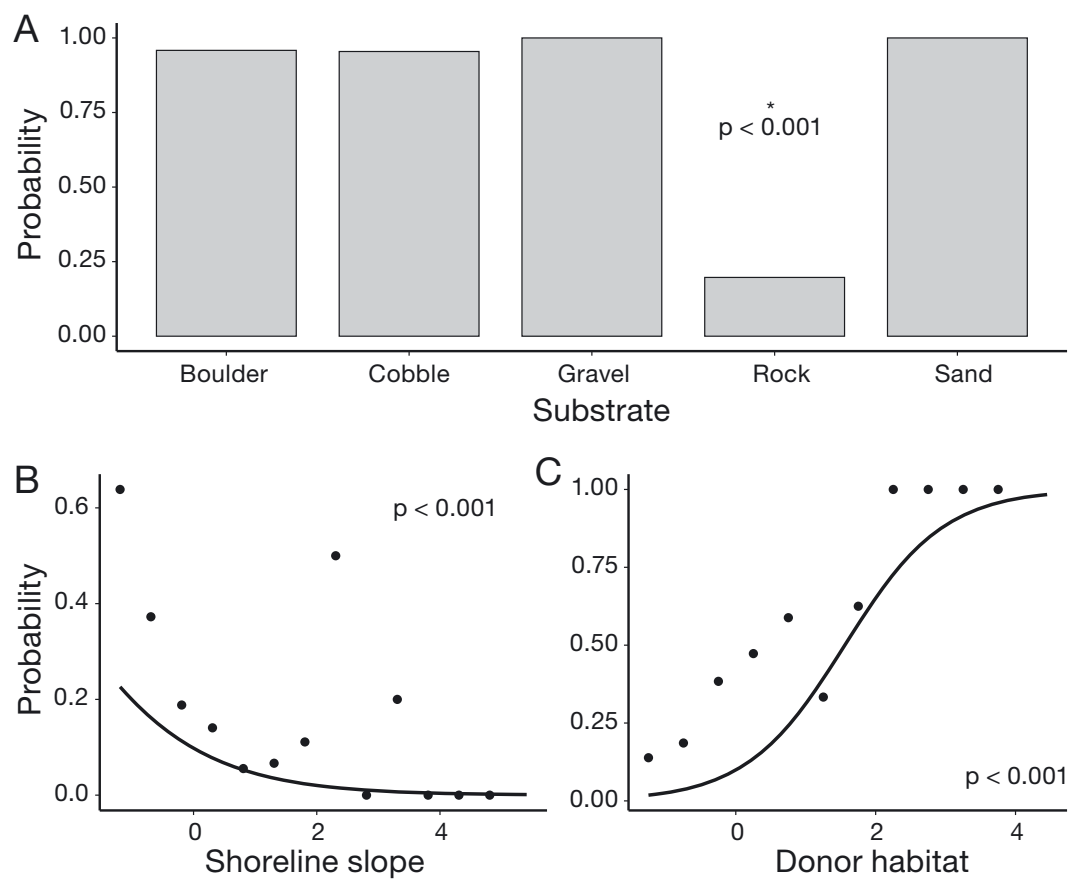

Fig. 4. Probability of wrack presence as a function of the significant terms: (A) substrate, (B) shoreline slope, and (C) extent of donor habitat from the topranking model predicting the presence or absence of wrack at 455 sites on 101 islands on the Central Coast of British Columbia. ( $\left.{ }^{*}\right)$ denotes significant difference among categories. Continuous predictor variables (shoreline slope and donor habitat) have been standardized by subtracting the mean and dividing by the standard deviation, and thus have no units

influence when predicting the presence of wrack on shorelines (Table 4, Fig. 4). None of the other 4 substrates significantly influenced wrack presence. Shoreline slope negatively influenced wrack accumulations (Table 4, Fig. 4). The extent of donor habitat within a $2 \mathrm{~km}$ radius had a positive influence on wrack presence (Table 4, Fig. 4).

For the biomass data set, which tested the predictors of accumulated wrack biomass at a site, the top model had 1 parameter: site (and the interactions between site variables; Table 3 ). This model indicated that a combination of aspect, slope, width, substrate, wave exposure, and interactions between slope and substrate best predicted wrack biomass accumulations (Table 3). Wave exposure and width significantly influenced the biomass of wrack accumulations (Table 5). Of the 6 categories of wave exposure (very protected, protected, semi-protected, semi-exposed, exposed, and very exposed), semiexposed exposures were positively correlated with wrack presence (Table 5, Fig. 5). The width of the shoreline, measured from the terrestrial edge to the water's edge at a consistent tidal height, also had a positive influence on wrack accumulations (Table 5, Fig. 5).

\subsection{Temporal surveys}

Wrack was present at all sites in all seasons (Fig. 6), but we found a significant difference in the amount of wrack deposited on a monthly basis $\left(\right.$ ANOVA $\left._{i} F_{5,174}=4.07, \mathrm{p}<0.002\right)$. These results were driven by differences in wrack accumulations between July and the winter months (Tukey multiple comparison of means; February $\mathrm{p}<0.03$, November $\mathrm{p}<0.009$, Fig. 6). There was a significant difference in wrack accumulation among sites $\left(\mathrm{ANOVA}_{i} F_{2,177}=4.39, \mathrm{p}<0.02\right)$, driven by a difference between North Beach and West Beach (Tukey multiple comparison of means $\mathrm{p}<0.02)$. We also found differences in species composition among months. Given the modest ANOSIM R estimate $(\mathrm{R}=0.23$ or 0.24 ) and the low number of replicates, we interpret these results conservatively and thus we consider there to be only moderate overlap in species composition for both month and site (Fig. S10, ANOSIM; factor $=$ month, $\mathrm{R}=0.24, \mathrm{p}<0.001$; factor $=$ site, $\mathrm{R}=$ $0.23, \mathrm{p}<0.05)$. North Beach had the most distinct biomass and species composition for each survey, driving the variation among sites in the ANOSIM

Table 5. Coefficient estimate, standard error (SE), and pvalue for each significant term in the top model (see Table 3) predicting wrack biomass accumulation as determined by the lowest $\mathrm{AIC}$ and highest $\mathrm{AIC}_{\mathrm{w}}$ scores. Coefficient estimate is standardized for continuous predictor variables (donor habitat). The first (alphabetical) term for categorical variables (wave exposure: exposed) is the reference/baseline for that category. $\times$ denotes interaction terms. Significant terms are in bold text

\begin{tabular}{|lrcl|}
\hline Variable & Estimate & $\mathrm{SE}$ & $\mathrm{p}$ \\
\hline Sine aspect & 0.21 & 0.29 & 0.5 \\
Cosine aspect & 0.39 & 0.31 & 0.2 \\
Shoreline width & $\mathbf{0 . 4 6}$ & $\mathbf{0 . 2 1}$ & $\mathbf{0 . 0 3}$ \\
Wave exposure: very protected & 2.06 & 2.06 & 0.1 \\
Wave exposure: protected & 1.73 & 1.20 & 0.2 \\
Wave exposure: semi-protected & 0.88 & 1.24 & 0.5 \\
Wave exposure: semi-exposed & $\mathbf{2 . 7 3}$ & $\mathbf{1 . 2 6}$ & $\mathbf{0 . 0 3}$ \\
Wave exposure: very exposed & 0.30 & 1.65 & 0.9 \\
Slope $\times$ Substrate: sand & -0.89 & 0.72 & 0.2 \\
Slope $\times$ Substrate: gravel & -0.19 & 0.96 & 0.9 \\
Slope $\times$ Substrate: cobble & -0.70 & 0.49 & 0.2 \\
Slope $\times$ Substrate: boulder & -1.02 & 0.64 & 0.1 \\
Slope $\times$ Substrate: rock & 0.86 & 0.57 & 0.1 \\
\hline
\end{tabular}



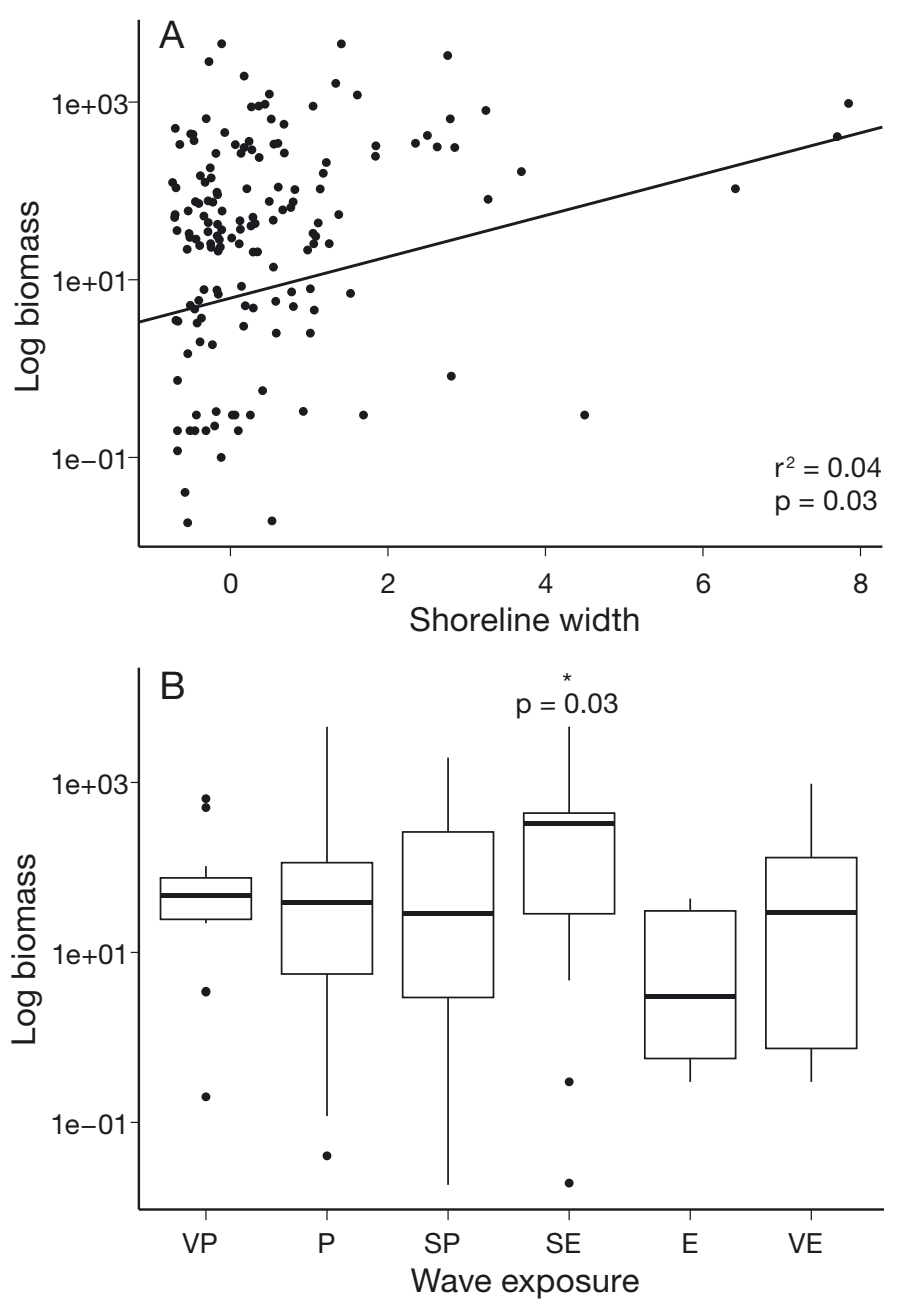

Fig. 5. Log wrack biomass as a function of model parameters with significant $(p<0.05)$ effects; $(A)$ shoreline width and $(B)$ wave exposure from the top-ranking model predicting biomass of wrack at 455 sites on 101 islands on the Central Coast of British Columbia. Categorizations for wave exposure are VP: very protected, P: protected, SP: semi-protected, SE: semiexposed, E: exposed, and VE: very exposed. $\left({ }^{*}\right)$ denotes significant difference among categories. Continuous predictor variable (shoreline width) has been standardized by subtracting the mean and dividing by the standard deviation, and thus has no units. Box plots show median value (solid horizontal line), upper and lower quartiles (box), and maximum and minimum values recorded (whiskers). Outliers $(\bullet)$ are also shown

results. Species diversity was higher in the summer $\left(H^{\prime}=2.02\right)$ than in the winter $\left(H^{\prime}=1.64\right)$.

The top contributors to the dissimilarities among all sites were N. luetkeana and Phyllospadix spp., (SIM$\mathrm{PER}_{i} N$. luetkeana average dissimilarity $=52 \%$, Phyllospadix spp. $=36 \%$ ). F. distichus was also a top contributor in explaining North Beach's dissimilarities to West and Fourth Beaches (SIMPER; average dissimilarity $=76 \%$ ). N. luetkeana and Phyllospadix spp. were again responsible for explaining dissimi-

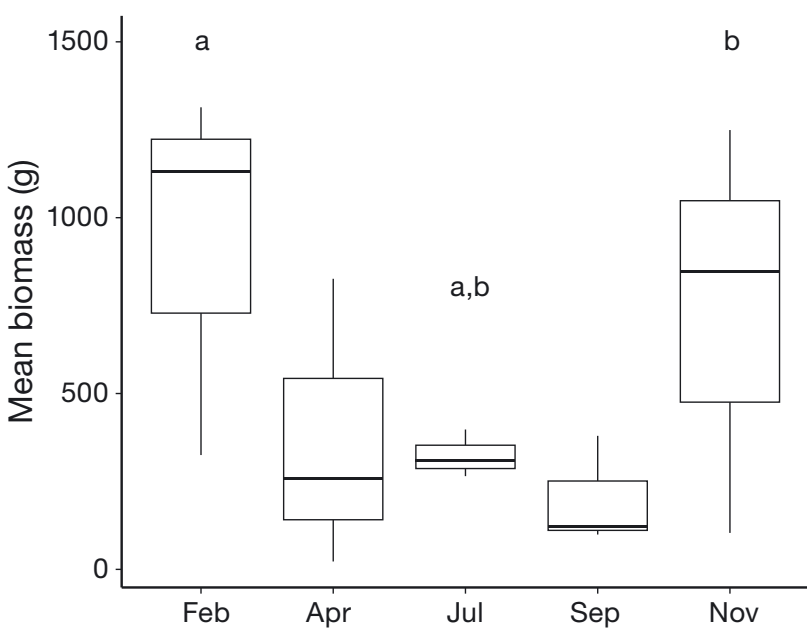

Fig. 6. Total dry wrack biomass per site at 5 different seasonal intervals. Box plots show median value (solid horizontal line), upper and lower quartiles (box), and maximum and minimum values recorded (whiskers). Mean biomass accumulation differed significantly between July and February $(p<0.03)$, and between July and November $(p<0.009)$, as indicated by letters above respective plots

larities among months (SIMPER; N. luetkeana average dissimilarity $=62 \%$, Phyllospadix spp. $=38 \%$ ). In addition, F. distichus was a top contributor in July (SIMPER; average dissimilarity $=44 \%$ ), and P. californica was a top contributor in February (SIMPER; average dissimilarity $=71 \%$ ). All SIMPER results for the cumulative contribution of the most influential species are summarized in Figs. S11 \& S12.

\section{DISCUSSION}

We conducted a multi-year survey of wrack deposits on 101 islands to explain patterns of wrack presence and accumulation along shorelines. Of the 3 broad factors considered (extent of nearby donor habitats, climate, and site characteristics) we found strong evidence that wrack accumulations were primarily driven by site characteristics and the donor habitat area. Climate events (i.e. wind, tide, swell) had little influence on wrack accumulation. However, the climate data used for analysis were short term. Further analysis of long-term climate data could provide more evidence for an effect of climate on wrack accumulations. Ocean currents, which we did not include in our models, are another broad factor that may affect wrack accumulations along this coastline, and we recommend this as an avenue for future studies. Finally, we also found that wrack depositions differed significantly temporally and compositionally 
(i.e. among species). As seen in other systems, these results indicate that wrack subsidies are varied, pulsed across both space and time, and have the potential to impact terrestrial productivity and diversity (Spiller et al. 2010, Filbee-Dexter et al. 2018, Fong \& Fong 2018).

Wrack accumulations varied in biomass across the study region, ranging from 0 to $6952 \mathrm{~g} \mathrm{~m}^{-2}$, with an average of $698 \mathrm{~g} \mathrm{~m}^{-2}$ in accumulated biomass per site. Previous research on sea wrack performed in Barkley Sound recorded dry biomass accumulations ranging from near 0 to almost $9 \mathrm{~kg} \mathrm{~m}^{-1}$ of shoreline across 6 sites in 1 season (Orr et al. 2005). A similar study in Oregon recorded wrack biomass accumulations across 12 sites in 2 seasons and found a maximum of $100 \mathrm{~g} \mathrm{~m}^{-2}$ in the summer and a maximum of $115 \mathrm{~g} \mathrm{~m}^{-2}$ in the fall (Reimer 2014). Notably, our surveys were the only surveys to record sites with zero accumulations and also the only surveys to include sites composed of rock or boulder substrates.

These results demonstrate that patterns in wrack biomass accumulations vary across the Pacific Northwest, which is not surprising as these sites differ in so many factors (i.e. physical characteristics, donor habitat species and productivity, climate). These results highlight the importance in determining accumulation rates specific to local geographies when considering wrack as a potential vector of marine nutrients. Below, we discuss the local factors (shoreline substrate, slope, wave exposure, width, and the extent of donor habitat) that affect the ability of sea wrack to permeate ecosystem boundaries on the Central Coast of BC.

\subsection{Spatial and temporal patterns of wrack accumulation}

The presence of sea wrack was significantly lower at sites with consolidated rocky substrates compared to sites with sand, gravel, cobble, or boulder substrates. Previous studies have confirmed that the volume of wrack along a shoreline decreases with a substratum's pore size (Valiela \& Rietsma 1995, Orr et al. 2005). Rock, having no pores and relatively high surface friction, does not retain wrack detritus to the same extent as sand, gravel, cobble, or boulder substrates do. Like many of the world's temperate coastlines, the Central Coast of BC has abundant rocky shorelines (Alaback \& Pojar 1997; Fig. 2). In fact, nearly $75 \%$ of the sites surveyed were classified as rock (Fig. S13). These small temperate islands with rocky shores accumulate less wrack along their shorelines, and thus fewer marine resources are available to terrestrial consumers. Therefore, in the context of boundary dynamics, wrack nutrient subsidy in this system relies on site permeability, which may significantly decrease nutrient arrival and thus dampen the expected relationship between island size and subsidy-enhanced productivity.

Shorelines with steeper slopes (i.e. cliffs, Fig. 2) were negatively correlated with wrack presence. This result aligns with our predictions based on the assumption that cliffs would provide gravity the opportunity to pull wrack off of a shoreline and back into the ocean. These findings are also consistent with results of previous studies from Australia and Spain, which reported negative associations between slope and the rate of wrack accumulations (Oldham et al. 2010, Barreiro et al. 2011). In contrast, Liebowitz et al. (2016) found that the biomass of shore-cast Phyllospadix spp. was positively correlated with steeper slopes, and suggested that this genus (which degrades slowly) can persist on steep shorelines when it is cast high up on the beach during peak high tides (Liebowitz et al. 2016). However, Liebowitz et al. (2016), Oldham et al. (2010), and Barreiro et al. (2011) all performed research on sandy beaches, whereas our research was conducted on a variety of shoreline substrates. We suggest that more buoyant seaweeds (i.e. species with pneumatocysts) could be retained on steep slopes when they are cast high upon the shoreline, and when this process does occur, it may permit a wrack subsidy to permeate islands with shorelines comprised of cliffs as either direct fertilization for shoreline flora or indirectly as an invertebrate food source.

The extent of donor habitat was a consistent driver of wrack presence, suggesting that the size and productivity of eelgrass beds, kelp forests, and Fucus distichus habitats are important factors when considering island archipelagos and convoluted shorelines, as fetch is reduced in these contexts and wrack is likely to wash ashore close to its site of detachment, creating predictability in marine resource subsidy availability. These results are consistent with similar findings on the coast of California, which tested the relationship between accumulated wrack biomass and extent of donor habitat within a $1 \mathrm{~km}$ radius of a site and found the extent of donor habitat to have a positive influence on accumulated wrack biomass (Liebowitz et al. 2016). However, because the coast of California differs geomorphologically from the Central Coast of $\mathrm{BC}$, these results have different implications in the context of rocky islands and the presence and extent of donor wrack species. Islands with permeable shorelines near large, productive donor habitats may receive more consistent wrack input than 
islands further away from donor habitats. Alternatively, impermeable islands with rock and cliff shorelines will not be able to accept wrack as a subsidy, regardless of the size or productivity of a donor bed. Additionally, the species composition of the habitat could affect the consistency of the subsidy, as eelgrass and Macrocystis pyrifera kelp are perennials and may contribute wrack to shorelines year-round. However, the kelp Nereocystis luetkeana is an annual and may contribute the bulk of its biomass as wrack to shorelines when it senesces during the fall/ winter storm season. Accordingly, the size, proximity, and species composition of the donor habitat, as well as the permeability of the recipient ecosystem, should be considered when investigating ecosystem connectivity and marine-terrestrial subsidy.

We found that shorelines with semi-exposed wave exposures were significantly positively associated with wrack biomass accumulations. This contrasts with other research, which described how reduced water flow in more protected wave exposures leads to greater wrack accumulations (Howd 2006, Barreiro et al. 2011). However, on the Central Coast, the moderate disturbance of semi-exposed shorelines may create more seaweed erosion and thus more floating wrack. The width of a shoreline was also positively associated with wrack accumulations. When considering these results together, we hypothesize that wider shorelines create a conducive environment for waves to push wrack accumulations on shore.

The processes that drive wrack species composition involve factors that operate at local scales. Although the species comprising wrack accumulations were ubiquitous across the study region, which indicates no influence of a latitudinal gradient on species composition, some species were present in higher abundances in certain nodes (Pterygophora californica in McMullin node, Zostera marina in Goose node, N. luetkeana in South Calvert node, and F. distichus in all nodes except McMullin). Abundances for some species can be readily explained; there is a large seagrass bed present in the Goose node, and historical sea otter colonization mediated a recent mass senescence of $P$. californica in the McMullin node (Rechsteiner et al. 2018). Accordingly, rocky intertidal shorelines (habitat for F. distichus) may be present throughout the region in relatively similar abundance. Our findings that indicated increased donor habitat adjacent to a site led to the presence of wrack on that same site's shoreline, may be especially important when considering other factors. For example, the physical characteristics of seaweed and kelp species (such as pneumatocysts that create buoyancy) may also influence the distribution pattern of wrack species to shorelines, allowing some species to travel further than others before being washed ashore or cast higher up the beach (Salomonsen et al. 1999, Hobday 2000, Flindt et al. 2007, Oldham 2014, Liebowitz et al. 2016).

Our results indicate that wrack was consistently present on shorelines throughout the year with pulses in seasonal accumulations. Many seaweeds in the northeast Pacific Ocean are annual species that grow only in the spring and summer (Druehl \& Clarkston 2016), which was consistent with our observations of a higher diversity of seaweed species onshore during these seasons. Accumulated biomass was higher in the winter, but with fewer species. Of the top biomass contributors, $N$. luetkeana displayed patterns of seasonal wrack deposition. This is expected for seaweeds with annual life histories. $N$. luetkeana grows from early spring to the fall (Mann 1973) and dislodgment due to winter storms likely accounts for the increased biomass we recorded at our sites. Species with perennial life histories are expected to display less pronounced seasonal signals (Liebowitz et al. 2016); however, our results demonstrated temporal dissimilarities for the perennials Phyllospadix spp., Pterygophora californica, and F. distichus. This suggests that seasonality may not affect patterns of wrack deposition and accumulation on the Central Coast of BC. More frequent temporal surveys could parse out whether seasonal patterns are dominant factors in wrack accumulation.

\subsection{Implications for island nutrient subsidies}

Our finding that shoreline substrate is a key factor in facilitating the arrival of wrack on islands has implications for the extent of island nutrient subsidies. Globally, the main avenue thought to facilitate the transfer of seaweed-derived nutrients to the terrestrial environment is the direct consumption of wrack by a large community of semi-terrestrial and terrestrial invertebrates (Lastra et al. 2008). Amphipods are considered one of the most abundant and ecologically important residents of beach ecosystems (sand, gravel, or cobble substrates), but are not found on rocky shorelines (Colombini \& Chelazzi 2003, Pelletier et al. 2011). On islands composed only of rocky shorelines, amphipods would not be able to facilitate the transfer of seaweed-derived nutrients and permeability would be restricted at these sites.

On islands with sand, gravel, or cobble substrates (capable of hosting amphipod populations), marine 
nutrient permeability to the islands' interior would be feasible. This vector of nutrient transfer would likely be intensified during the summer months, which is the active season for amphipods (Pelletier et al. 2011). Amphipods preferentially feed on aged wrack over freshly deposited seaweed material, although there is no clear amphipod preference for a particular seaweed species (Pennings et al. 2000, Mews et al. 2006). Therefore, an amphipod's variation in wrack preferences enables a range of diet opportunities. This is ideal during the summer months because wrack accumulations are lower, but wrack species diversity is higher. This adaptation allows amphipods to exploit this marine resource and enables the subsidy to permeate island shorelines that are composed of sand, gravel, or cobble.

Permeability to subsidies is likely to depend on the specific vector being considered. Other vectors of marine-terrestrial subsidies (such as fog, sea spray, humans, and river otters Lontra canadensis) fertilize terrestrial soils with marine-derived nitrogen and other nutrients (Ben-David et al. 1998, Whipkey et al. 2000, Ewing et al. 2009, Trant et al. 2016) and were ubiquitous in the study region. Such vectors could contribute to patterns of productivity in this area and beyond. Fog, sea spray, humans, and river otters each have distinct behaviors that would affect their ability to permeate into island interiors and would likely be less deflected by steep, rocky shorelines than sea wrack is. However, the direct effects of these vectors are limited to the edges of islands: trees and shrubs can create a relatively impermeable boundary for fog and sea spray (Ewing et al. 2009), historical humans created 'shell middens' (large piles of bi-valve shells) at habitation sites in bays and estuaries (Fisher et al. 2019), and river otters tend to create latrines and dens near the terrestrial edges of coastlines (Ben-David et al. 1998). Nevertheless, in contrast to sea wrack, communities on rocky islands would still be able to accept these vectors of nutrient flow. On steep, rocky islands along the BC Central Coast (impermeable to sea wrack penetration into the island interior), these 4 vectors of marine nutrient subsidies (fog, sea spray, humans, and river otters) could affect terrestrial productivity. The specific permeability characteristics of a vector should be considered when evaluating the flow of nutrients across ecosystem boundaries.

\subsection{Conclusions}

Our research reveals that on BC's Central Coast, sea wrack is present on shorelines close to large donor habitats and is not present on rocky or steep shorelines. Additionally, wrack accumulates on wide, semi-wave-exposed shorelines. Six dominant species of seaweeds and seagrasses ( $F$. distichus, $M$. pyrifera, $N$. luetkeana, P. californica, Zostera marina, and Phyllospadix spp.) had a consistent presence on shorelines throughout the year but displayed pulses in biomass accumulations and species composition. These results confirm the potential of sea wrack as a vector of marine resources to islands with beach shorelines. This marine-terrestrial nutrient subsidy may affect the productivity of terrestrial consumers on permeable islands, as other marine resources have been shown to do in low-productivity terrestrial environments (Polis \& Hurd 1996, Stapp \& Polis 2003, Maron et al. 2006, Mellbrand et al. 2011, Adame et al. 2015). Further research investigating terrestrial species diversity and abundance at these sites can determine the effects, if any, sea wrack has on temperate terrestrial communities in high productivity environments.

Acknowledgements. We thank colleagues from the Heiltsuk and Wuikinuxv First Nations for the opportunity to perform this research on the Central Coast of $\mathrm{BC}$. This research is a component of the Hakai Institute's 100 Islands Project. We deeply appreciate the field, laboratory, and funding support from the Hakai Institute, the Tula Foundation, the Natural Sciences and Engineering Research Council of Canada, the Ian McTaggart Cowan Professorship, the Canada Foundation for Innovation, and a Mitacs Accelerate grant, which made this research possible. Thank you also to Will McInnes of the Hakai Institute for GIS support. We are grateful to Carl Humchitt and Beatrice Proudfoot for insights and discussions during field and laboratory work and to Chris Madsen, Kalina Hunter, Katie Davidson, and Darienne Lancaster for assistance during winter field work. We also thank Natalie Ban, Katy Hind, Donald Kramer, and 4 anonymous reviewers for helpful manuscript edits.

\section{LITERATURE CITED}

Adame MF, Fry B, Gamboa JN, Herrera-Silveira JA (2015) Nutrient subsidies delivered by seabirds to mangrove islands. Mar Ecol Prog Ser 525:15-24

Alaback P, Pojar J (1997) Vegetation from ridgetop to seashore. In: Schoonmaker PK, von Hagen B, Wolf EC (eds) The rainforests of home: profile of a North American Bioregion. Island Press, Washington, DC, p 69-87

Anderson WB, Polis GA (1999) Nutrient fluxes from water to land: Seabirds affect plant nutrient status on Gulf of California islands. Oecologia 118:324-332

Anderson WB, Wait DA (2001) Subsidized island biogeography hypothesis: another new twist on an old theory. Ecol Lett 4:289-291

Barreiro F, Gómez M, Lastra M, López J, de la Huz R (2011) Annual cycle of wrack supply to sandy beaches: effect of the physical environment. Mar Ecol Prog Ser 433:65-74 
Barrett K, Anderson WB, Wait DA, Grismer LL, Polis GA, Rose MD (2005) Marine subsidies alter the diet and abundance of insular and coastal lizard populations. Oikos 109:145-153

Ben-David M, Bowyer RT, Duffy LK, Roby DD, Schell DM (1998) Social behavior and ecosystem processes: river otter latrines and nutrient dynamics of terrestrial vegetation. Ecology 79:2567-2571

Burnham KP, Anderson DR (1998) Model selection and multimodel inference: a practical information-theoretic approach. Springer Verlag, New York, NY

Burnham KP, Anderson DR, Huyvaert KP (2011) AIC model selection and multimodel inference in behavioral ecology: some background, observations, and comparisons. Behav Ecol Sociobiol 65:23-35

* Cardona L, García M (2008) Beach-cast seagrass material fertilizes the foredune vegetation of Mediterranean coastal dunes. Acta Oecol 34:97-103

* Carlton JT, Hodder J (2003) Maritime mammals: terrestrial mammals as consumers in marine intertidal communities. Mar Ecol Prog Ser 256:271-286

Catenazzi AA, Donnelly M (2007) The Ulva connection: marine algae subsidize terrestrial predators in coastal Peru. Oikos 116:75-86

* Chapman ARO, Johnson CR (1990) Disturbance and organization of macroalgal assemblages in the Northwest Atlantic. Hydrobiologia 192:77-121

* Clarke KR (1993) Non-parametric multivariate analyses of changes in community structure. Aust J Ecol 18:117-143

Colombini I, Chelazzi L (2003) Influence of marine allochthonous input on sandy beach communities. Oceanogr Mar Biol Annu Rev 41:115-159

* Colombini I, Aloia A, Fallaci M, Pezzoli G, Chelazzi L (2000) Temporal and spatial use of stranded wrack by the macrofauna of a tropical sandy beach. Mar Biol 136:531-541

* de Bettignies T, Wernberg T, Lavery PS, Vanderklift MA, Mohring MB (2013) Contrasting mechanisms of dislodgement and erosion contribute to production of kelp detritus. Limnol Oceanogr 58:1680-1688

Wel Vecchio S, Marbà N, Acosta ATR, Vignolo C, Traveset A (2013) Effects of Posidonia oceanica beach-cast on germination, growth and nutrient uptake of coastal dune plants. PLOS ONE 8:e70607

Druehl LD, Clarkston BE (2016) Pacific seaweeds: a guide to common seaweeds of the West Coast. Harbour Publishing, Madeira Park, BC

Druehl LD, Wheeler WN (1986) Population biology of Macrocystis integrifolia from British Columbia, Canada. Mar Biol 90:173-179

Dugan JE, Miller R (2019) Dataset: Starting and ending locations of five transects at each of three kelp study sites in Santa Barbara Channel, 2015 to 2017. https://www.bcodmo.org/dataset/737366

Dugan JE, Hubbard DM, McCrary MD, Pierson MO (2003) The response of macrofauna communities and shorebirds to macrophyte wrack subsidies on exposed sandy beaches of southern California. Estuar Coast Shelf Sci 58(Suppl):25-40

Ewing HA, Weathers KC, Templer PH, Dawson TE, Firestone MK, Elliott AM, Boukili VKS (2009) Fog water and ecosystem function: heterogeneity in a California redwood forest. Ecosystems 12:417-433

Filbee-Dexter K, Wernberg T, Norderhaug KM, RamirezLlodra E, Pedersen MF (2018) Movement of pulsed resource subsidies from kelp forests to deep fjords. Oecologia 187:291-304
Fisher JA, Shackelford N, Hocking MD, Trant AJ, Starzomski BM (2019) Indigenous peoples' habitation history drives present day forest biodiversity in British Columbia's coastal temperate rainforest. People Nat: 103-114

* Flindt MR, Pedersen CB, Amos CL, Levy A, Bergamasco A, Friend PL (2007) Transport, sloughing and settling rates of estuarine macrophytes: mechanisms and ecological implications. Cont Shelf Res 27:1096-1103

Fong CR, Fong P (2018) Nutrient fluctuations in marine systems: press versus pulse nutrient subsidies affect producer competition and diversity in estuaries and coral reefs. Estuaries Coasts 41:421-429

Fox CH, Paquet PC, Reimchen TE (2015) Novel species interactions: American black bears respond to Pacific herring spawn. BMC Ecol 15:14

* Graler B, Pebesma EJ, Heuvelink G (2016) Spatio-temporal interpolation using gstat. R J 8:204-218

Hargrove WW, Hoffman FM (2004) Potential of multivariate quantitative methods for delineation and visualization of ecoregions. Environ Manag 34(Suppl 1):S39-S60

Harper JR, Morris MC (2014) Alaska ShoreZone Coastal Habitat Mapping Protocol. Nuka Research and Planning LLC.;. Seldovia, AK

*Harrold C, Lisin S (1989) Radio-tracking rafts of giant kelp: local production and regional transport. J Exp Mar Biol Ecol 130:237-251

*Hobday AJ (2000) Abundance and dispersal of drifting kelp Macrocystis pyrifera rafts in the Southern California Bight. Mar Ecol Prog Ser 195:101-116

Howd P (2006) Beach processes and sedimentation, $2^{\text {nd }}$ edn. Prentice-Hall, Englewood Cliffs, NJ

Howes D, Harper JR, Owens E (1994) Physical shore-zone mapping system for British Columbia. https://www2.gov. bc.ca/assets/gov/data/geographic/topography/bc_shore zonemappingsyste.pdf

Ince R, Hyndes GA, Lavery PS, Vanderklift MA (2007) Marine macrophytes directly enhance abundances of sandy beach fauna through provision of food and habitat. Estuar Coast Shelf Sci 74:77-86

* Jackson JM, Thomson RE, Brown LN, Willis PG, Borstad GA (2015) Satellite chlorophyll off the British Columbia Coast, 1997-2010. J Geophys Res Oceans 120: 4709-4728

* Jiménez MA, Beltran R, Traveset A, Calleja ML, DelgadoHuertas A, Marbà N (2017) Aeolian transport of seagrass (Posidonia oceanica) beach-cast to terrestrial systems. Estuar Coast Shelf Sci 196:31-44

Koop K, Field JG (1980) The influence of food availability on population dynamics of a supralittoral isopod, Ligia dilatata Brandt. J Exp Mar Biol Ecol 48:61-72

Krumhansl KA, Scheibling RE (2011) Detrital production in Nova Scotian kelp beds: patterns and processes. Mar Ecol Prog Ser 421:67-82

KKuznetsova A, Brockhoff PB, Christensen RH (2017) lmerTest Package: tests in linear mixed effects models. J Stat Softw 82:1-26

KLastra M, Page HM, Dugan JE, Hubbard DM, Rodil IF (2008) Processing of allochthonous macrophyte subsidies by sandy beach consumers: estimates of feeding rates and impacts on food resources. Mar Biol 154:163-174

Lastra M, Rodil IF, Sanchez-Mata A, Garcia-Gallgo M, Mora $\mathrm{J}$ (2014) Fate and processing of macroalgal wrack subsidies in beaches of Deception Island, Antarctic Peninsula. J Sea Res 88:1-10 
Lewis TL, Mews M, Jelinski DE, Zimmer M (2007) Detrital subsidy to the supratidal zone provides feeding habitat for intertidal crabs. Estuaries Coasts 30:451-458

Liebowitz DM, Nielsen KJ, Dugan JE, Morgan SG and others (2016) Ecosystem connectivity and trophic subsidies of sandy beaches. Ecosphere 7:e01503

López BA, Macaya EC, Jeldres R, Valdivia N, Bonta CC, Tala F, Thiel M (2019) Spatio-temporal variability of strandings of the southern bull kelp Durvillaea antarctica (Fucales, Phaeophyceae) on beaches along the coast of Chilelinked to local storms. J Appl Phycol 31:2159-2173

* MacMillan MR, Quijón PA (2012) Wrack patches and their influence on upper-shore macrofaunal abundance in an Atlantic Canada sandy beach system. J Sea Res 72:28-37

Mann KH (1973) Seaweeds: their productivity and strategy for growth. Science 182:975-981

Maron JL, Estes JA, Croll DA, Danner EM, Elmendorf SC, Buckelew SL (2006) An introduced predator alters Aleutian Island plant communities by thwarting nutrient subsidies. Ecol Monogr 76:3-24

McCauley DJ, DeSalles PA, Young HS, Dunbar RB, Dirzo R, Mills MM, Micheli F (2012) From wing to wing: the persistence of long ecological interaction chains in lessdisturbed ecosystems. Sci Rep 2:409

Meidinger DV, Pojar J (1991) Ecosystems of British Columbia. BC Ministry of Forests, Victoria

* Mellbrand K, Lavery PS, Hyndes GA, Hambäck PA (2011) Linking land and sea: different pathways for marine subsidies. Ecosystems 14:732-744

Mews M, Zimmer M, Jelinski DE (2006) Species-specific decomposition rates of beach-cast wrack in Barkley Sound, British Columbia, Canada. Mar Ecol Prog Ser 328:155-160

Nijland W, Reshitnyk LY, Starzomski BM, Reynolds JD, Darimont CT, Nelson TA (2017) Deriving rich coastal morphology and shore zone classifications from LIDAR terrain models. J Coast Res 33:949-958

Oksanen J, Blanchet FG, Friendly M, Kindt R and others (2017) vegan: Community Ecology Package. R package version 3.5.2. https://CRAN.R-project.org/package=vegan

Oldham CE (2014) A preliminary exploration of the physical properties of seagrass wrack that affect its offshore transport, deposition and retention on a beach. Limnol Oceanogr 4:120-135

Oldham CE, Lavery PS, McMahon K, Pattiaractchi C, Chiffings TW (2010) Seagrass wrack dynamics in Geographe Bay, Western Australia. https://www.ecu.edu.au/_data/ assets/pdf_file/0008/728774/Seagrass-Wrack-DynamicsLR.pdf

Orr M, Zimmer M, Jelinski DE, Mews M (2005) Wrack deposition on different beach types: spatial and temporal variation in the pattern of subsidy. Ecology 86:1496-1507

Pebesma EJ (2004) Multivariable geostatistics in S: the gstat package. Comput Geosci 30:683-691

Pelletier AJD, Jelinski DE, Treplin M, Zimmer M (2011) Colonisation of beach-cast macrophyte wrack patches by talitrid amphipods: a primer. Estuaries Coasts 34:863-871

Pennings SC, Carefoot TH, Zimmer M, Danko JP, Ziegler A (2000) Feeding preferences of supralittoral isopods and amphipods. Can J Zool 78:1918-1929

Pinheiro J, Bate D, DebRoy S, Sarkar D, R Core Team (2018) nlme: Linear and nonlinear mixed effects models. R package version 2.5.2. https://CRAN.R-project.org/package= nlme

Polis GA, Hurd SD (1996) Linking marine and terrestrial food webs: allochthonous input from the ocean supports high secondary productivity on small islands and coastal land communities. Am Nat 147:396-423

R Core Team (2018) R: a language and environment for statistical computing. R Foundation for Statistical Computing, Vienna

Rechsteiner EU, Wickham SB, Watson JC (2018) Predator effects link ecological communities: Kelp created by sea otters provides an unexpected subsidy to bald eagles. Ecosphere 9:e02271

Reimer JN (2014) Patterns of macrophyte wrack deposition on sandy beaches of the Pacific Northwest coast, USA. MSc thesis, Oregon State University, Corvallis, OR

Reshitnyk LY, Denouden T, McInnes WS, Hessing-Lewis M, Prentice C, Short F (2016) Estimating seagrass extent in coastal British Columbia. Technical Report, Hakai Institute, Victoria

Roberts DW (1986) Ordination on the basis of fuzzy set theory. Vegetatio 66:123-131

Kose MD, Polis GA (1998) The distribution and abundance of coyotes: the effects of allochthonous food subsidies from the sea. Ecology 79:998-1007

Salomonsen J, Flindt M, Geertz-hansen O, Johansen C (1999) Modelling advective transport of Ulva lactuca (L) in the sheltered bay, Mollekrogen, Roskilde Fjord, Denmark. Hydrobiologia 397:241-252

Schlacher TA, Hutton BM, Gilby BL, Porch N and others (2017) Algal subsidies enhance invertebrate prey for threatened shorebirds: a novel conservation tool on ocean beaches? Estuar Coast Shelf Sci 191:28-38

Seymour RJ, Tegner MJ, Dayton PK, Parnell PE (1989) Storm wave induced mortality of giant kelp, Macrocystis pyrifera, in southern California. Estuar Coast Shelf Sci 28:277-292

Sosik EA, Simenstad CA (2013) Isotopic evidence and consequences of the role of microbes in macroalgae detritusbased food webs. Mar Ecol Prog Ser 494:107-119

Spiller DA, Piovia-Scott J, Wright AN, Yang LH, Takimoto G, Schoener TW, Iwata T (2010) Marine subsidies have multiple effects on coastal food webs. Ecology 91:1424-1434

* Stapp P, Polis GA (2003) Marine resources subsidize insular rodent populations in the Gulf of California, Mexico. Oecologia 134:496-504

Steneck RS, Dethier MN (1994) A functional group approach to the structure of algal-dominated communities. Oikos 69:476-498

Stenton-Dozey JME, Griffiths CL (1983) The fauna associated with kelp stranded on a sandy beach. In: McLachlan A, Erasmus T (eds) Sandy beaches as ecosystems. Developments in Hydrobiology 19. Springer, Dordrecht, p 321-380

Suursaar Ü, Torn K, Martin G, Herkül K, Kullas T (2014) Formation and species composition of stormcast beach wrack in the Gulf of Riga, Baltic Sea. Oceanologia 56:673-695

Thomson RE (1981) Oceanography of the British Columbia Coast. Can Spec Publ Fish Aquat Sci 56. DFO, Ottawa

* Trant AJ, Nijland W, Hoffman KM, Mathews DL, McLaren D, Nelson TA, Starzomski BM (2016) Intertidal resource use over millennia enhances forest productivity. Nat Commun 7:12491

*Valiela I, Rietsma CS (1995) Disturbance of salt marsh vegetation by wrack mats in Great Sippewissett Marsh. Oecologia 102:106-112

*Villares R, Fernandez-Lema E, Lopez-Mosquera ME (2016) Evaluation of beach wrack for use as an organic fertilizer: temporal survey in different areas. Thalassas 32:19-36 
Waters JM, King TM, Fraser CI, Craw D (2018) Crossing the front: contrasting storm-forced dispersal dynamics revealed by biological, geological and genetic analysis of beach-cast kelp. J R Soc Interface 15:20180046

Wentworth CK (1922) A scale of grade and class terms for clastic sediments. J Geol 30:377-392

Whipkey CE, Capo RC, Chadwick OA, Stewart BW (2000) The importance of sea spray to the cation budget of a coastal Hawaiian soil: a strontium isotope approach. Chem Geol 168:37-48

Wickham SB, Darimont CT, Reynolds JD, Starzomski BM (2019) Species-specific wet-dry mass calibrations for dominant Northeastern Pacific Ocean macroalgae and macrophytes. Aquat Bot 152:27-31

Editorial responsibility: Thomas Wernberg, Crawley, Western Australia, Australia
Wiens JA, Crawford CS, Gosz JR (1985) Boundary dynamics: a conceptual framework for studying landscape ecosystems. Oikos 45:421-427

*Wilmers CC, Estes JA, Edwards M, Laidre KL, Konar B (2012) Do trophic cascades affect the storage and flux of atmospheric carbon? An analysis of sea otters and kelp forests. Front Ecol Environ 10:409-415

WWitman JD (1987) Subtidal coexistence: storms, grazing, mutualism, and the zonation of kelps and mussels. Ecol Monogr 57:167-187

Zuur AF, Leno EN, Walker NJ, Saveliev AA, Smith GM (2009) Mixed effects models and extensions in ecology with R. Springer Science \& Business Media, New York, NY

Submitted: April 2, 2019; Accepted: November 11, 2019

Proofs received from author(s): January 30, 2020 